\title{
Correction to: Urbanisation and nest building in birds: a review of threats and opportunities
}

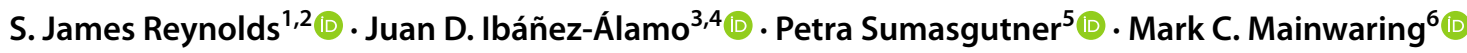

Published online: 5 April 2021

(c) The Author(s) 2021

Correction to: Journal of Ornithology (2019) 160:841-860
https://doi.org/10.1007/s10336-019-01657-8

In the original publication of the article, Table 2 was published containing an error. With reference to the observational study of nesting House Crows (Corvus splendens) by Sohi and Kler (2017), the authors wrongly reported the nest site as "Nestbox" when it should have been described as "Platform nest in several tree species". The authors are most grateful to Anne Clark of Binghamton University, Binghamton, NY, USA for bringing this mistake to their attention.

Publisher's Note Springer Nature remains neutral with regard to jurisdictional claims in published maps and institutional affiliations.

The original article can be found online at https://doi.org/10.1007/ s10336-019-01657-8.

S. James Reynolds

J.Reynolds.2@bham.ac.uk

1 Centre for Ornithology, School of Biosciences, College of Life and Environmental Sciences, University of Birmingham, Edgbaston, Birmingham B15 2TT, UK

2 The Army Ornithological Society (AOS), c/o Prince Consort Library, Knollys Road, Aldershot GU11 1PS, Hampshire, UK

3 Groningen Institute for Evolutionary Life Sciences, University of Groningen, 9700 Groningen, The Netherlands

4 Present Address: Department of Zoology, Faculty of Sciences, University of Granada, 18071 Granada, Spain

5 Department of Biological Sciences, FitzPatrick Institute of African Ornithology, DST-NRF Centre of Excellence, University of Cape Town, Rondebosch, Cape Town, South Africa

6 Division of Biological Sciences, University of Montana, Missoula, MT 59812, USA 